\begin{tabular}{lcl}
\hline PKS & REVISTA DE GEOGRAFIA & OJS \\
$\begin{array}{l}\text { PUBLIC } \\
\text { KNOWLEDGE }\end{array}$ & (RECIFE) & $\begin{array}{l}\text { OPEN } \\
\text { PROJECT }\end{array}$ \\
\hline
\end{tabular}

\title{
CENTRALIDADE URBANO-REGIONAL DA PECUÁRIA DE ARAGUAÍNA-TO: A CAPITAL DO BOI GORDO?
}

\author{
Roberto Antero da Silva ${ }^{1}$ \\ ${ }^{1}$ Universidade Federal do Tocantins (UFT). Email: robertoantero@uft.edu.br
}

Artigo recebido em 12/08/2016 e aceito em 24/06/2017

\begin{abstract}
RESUMO
$\mathrm{O}$ artigo discute a centralidade urbano-regional de Araguaína, cidade média da Amazônia brasileira, mediadora de acumulação da pecuária capitalista, e que recebe o cognome de capital do boi gordo. Concentra em seu espaço urbano empresas multinacionais e nacionais que controlam o beneficiamento e a comercialização da produção regional, e, nas principais avenidas corredores se especializam na distribuição de bens e serviços de apoio a pecuária, caracterizando a cidade como expressão desta atividade econômica. A metodologia operacional utilizada combina fontes bibliográficas, dados socioeconômicos e pesquisa direta. Aborda-se de maneira particular sobre uso do espaço urbano pela pecuária, destacando como esta atividade econômica atribui o perfil do que é a cidade propriamente dita, inclusive no clichê que se cria em relação a ela.
\end{abstract}

Palavras-chaves: Araguaína-TO. Centralidade. Urbano-regional. Pecuária

\section{LIVESTOCK URBAN-REGIONAL CENTRALITY OF ARAGUAÍNA- TO: A CAPITAL DO BOI GORDO?}

\begin{abstract}
This article discusses the urban and regional centrality of Araguaína, a middle important city in in the Brazilian Amazon region. It is called by the epithet capital do boi gordo because it receives the wealth from livestock. It concentrates in its urban space diverse national and multinational enterprises located in the main avenues which control the commercialization of the regional production as well as the provide service works and goods, so these economic activities are among its characteristics. The methodology used is based on bibliography source, socioeconomic data and personal interview. It is also discussed the urban space used by farming highlighting the way this economic activity has affected the profile of the city including a kind of commonplace phrase related to it and makes it famous because that's.
\end{abstract}

Keywords: State of Alagoas; Institutionalization; metropolis; region. 


\section{INTRODUÇÃO}

Araguaína é dotada de infraestrutura econômica urbana e regional de apoio a pecuária. Como cidade mediadora de acumulação da pecuária capitalista, concentra empresas multinacionais e nacionais que controlam o beneficiamento e a comercialização da produção regional, com ruas e avenidas que se transformam em corredores especializados na distribuição de bens e serviços de apoio a produção primária, caracterizando a cidade como expressão dessa atividade econômica.

Localizada ao norte do estado do Tocantins, Araguaína é integrante da Amazônia Legal (Figura 1), destaca-se peculiaridade de rápida transformação de fronteira agrícola transmutada em cidade de influência regional, constituindo parte da região econômica periférica, porém inserida no mercado mundial.

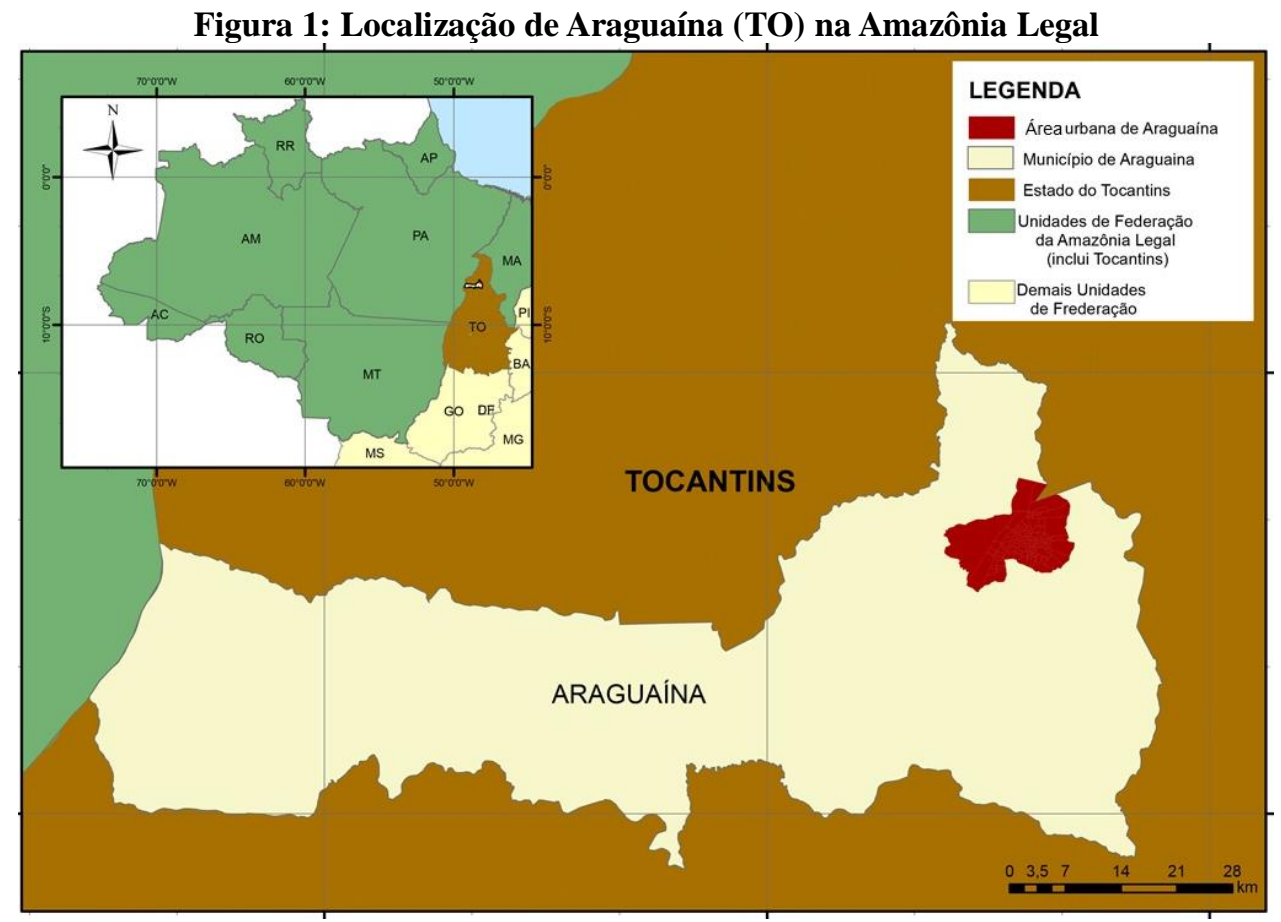

Fonte: IBGE. Censo demográfico 2010. Elaborado pelo autor.

Examina-se a centralidade socioeconômica na interpretação dos conteúdos e significados da urbanização para compreender a dinâmica e funções que definem o significado desta cidade para si e para sua região.

Estuda-se a cidade para explicitar o marketing e os mitos da capital do boi gordo (TOCANTINS, 2009), cognome aceito na sociedade tocantinense e que se mantém apesar de 
sua rápida e intensa urbanização e do crescimento como centro comercial e de prestação de serviços para diversos setores econômicos e sociais com relevância para serviços de educação superior e saúde.

Em Araguaína, a maior fonte de riqueza é de origem terciária. O Produto Interno Bruto municipal é proveniente na sua maior parte de serviços, com $71 \%$, seguido da indústria, com 24,69\%, por último a agropecuária contribuindo em 4,31\% (IBGE, 2009).

$\mathrm{Na}$ apreciação sintética dos dados, a pecuária aparenta-se como inexpressiva atividade econômica, representando contradição em relação ao cognome capital do boi gordo. No entanto, argumentamos que a centralidade estadual na captação e exportação de carne bovina; o espaço urbano que assume o perfil desta atividade econômica; o marketing sustentando pelo sindicato patronal, e comércio especializado, reforçam tal denominação. Araguaína possui feição regional em função de uma atividade que assume importância determinante, inclusive no clichê que se cria em relação a ela.

Em termos de objetivos a pesquisa se propõe a explicitar as centralidades urbanoregionais da produção agropecuária de Araguaína, com suas agroindústrias de exportação; do comércio e serviços especializados em insumos, máquinas e serviços relacionados à expansão capitalista na Amazônia e avanço da pecuária bovina com suas novas perspectivas no mercado mundial.

A metodologia combina fontes bibliográficas; levantamento de dados estatísticos, em maioria coletados online, no Instituto Brasileiro de Geografia e Estatística (IBGE), no Ministério do Desenvolvimento, Indústria e Comércio Exterior, em instituições públicas de apoio à pecuária em Araguaína; e pesquisa direta que teve como objetivo captar e espacializar a centralidade urbana da produção pecuária na cidade de Araguaína, em comércio e serviços especializados, agroindústrias e instituições.

\section{ARAGUAÍNA: CIDADE MÉDIA DA AMAZÔNIA}

A incorporação da Amazônia como fronteira econômica nacional a partir de 1960 ocorre sob o comando estatal que age como viabilizador dos interesses econômicos privados, com maciças intervenções que determinaram a atual realidade urbana e regional (BECKER, 1990). 
$\mathrm{Na}$ inserção da Amazônia no processo de acumulação capitalista, as cidades assumem papéis fundamentais, conforme Becker (1990, p.44) "uma fronteira urbana é a base logística para o projeto de rápida ocupação da região".

As políticas espaciais comandadas pelo Estado na região transformaram o espaço de Araguaína. Utilizando a terminologia de Lefebvre (2001), o espaço urbano implode-explode articulado ao processo de regionalização econômica.

Impressiona a velocidade com que atrai contingente populacional e passa de pequena cidade para cidade média em apenas meio século. Na década de 1950, Araguaína caracterizava-se como um pequeno e isolado povoado. Na década seguinte emergiu para a condição de município, apresentando no espaço as marcas de rápidas e intensas transformações sociais e econômicas. Os rápidos e volumosos movimentos migratórios determinaram o crescimento populacional e transformações espaciais no município, sobretudo na cidade sede. De 1960 à 2010, a população explodiu de 10.826 habitantes para 150.520 (IBGE, 1970, 2010).

As cidades ganham relevância no contexto econômico regional atuando como espaço para ampliação do capital, em especial aquelas consideradas como cidades médias.

De acordo com Lefebvre a cidade capitalista não é somente expressão da urbanização, mas de todo processo de produção capitalista do espaço, pois:

\footnotetext{
Tornando-se centro de decisão ou antes agrupando os centros de decisão, a cidade moderna intensifica, organizando-a, a exploração de toda a sociedade (não apenas da classe operária como também de outras classes sociais não dominantes). Isto é dizer que ela não é um lugar passivo da produção ou da concentração dos capitais, mas sim que o urbano intervém como tal na produção (nos meios de produção) (LEFEBVRE, 2001, p. 63).
}

Neste contexto estão inseridas as cidades médias. Conforme aponta Corrêa (2007), quando se refere sobre este tipo especifico de cidade é preciso considerar a combinação entre tamanho demográfico, funções urbanas e a organização do seu espaço intra-urbano.

Nesta pesquisa uma questão primordial a ser considerada está relacionada à competência de ofertar bens e serviços.

Papéis regionais sempre estiveram associados às cidades médias, às vezes denominadas cidades regionais. Assim pensada, cada cidade média associava-se à área ou à região que comandava, o que pressupunha relações diretas com um número de cidades pequenas e o desempenho de funções de intermediação destas com a cidade maior de que eram todas tributárias, tanto a cidade média como as pequenas (SPOSITO, 2007, p. 234) 
A importância de uma cidade média tem relação direta com a área ou região sobre a qual ela é capaz de exercer influência, que por sua vez estão subordinadas com certa hierarquia, indiretamente às cidades maiores, e, diretamente, ao processo de acumulação capitalista. Conforme aponta Trindade Jr. e Pereira (2007, p. 316), “são produtoras/distribuidoras de bens e serviços exigidos por elas e por um conjunto de cidades menores que existem em seu entorno".

Neste caso, a cidade média de Araguaína atua como distribuidora de bens e serviços, dentre os quais os de apoio à agropecuária, que são demandadas por si mesma, bem como para as cidades do seu entorno, em que também exerce influência comandado e captando a produção de matéria prima.

A afirmação de Araguaína como cidade média considera o trabalho de Castello Branco (2006) e o documento de REGIC/IBGE (2008). No primeiro exemplo dá-se maior relevância à confirmação da condição deste tipo de cidade, demandando revisão da classificação proposta por Castello Branco (2006), que Araguaína figure com a tipologia de incipiente, a menor hierarquia entre as cidades médias brasileiras, que, neste caso, possui mais três tipologias: baixas, médias e complexas.

O próprio documento Regiões de Influência das Cidades do IBGE (2008) atualiza esta hierarquia ao classificar Araguaína como capital regional B, nos mesmos níveis de Marabá (PA) e Imperatriz (MA). No Tocantins apenas a capital Palmas tem maior hierarquia ao figurar como capital regional A.

$\mathrm{Na}$ atualidade, reconhece-se uma participação cada vez mais crescente das cidades médias, como expressão da tendência de urbanização amazônica. Neste cenário desempenham no contexto econômico, político e social importantes funções, exercendo centralidades urbano-regionais na região de influência, a exemplo de Marabá e Santarém (TRINDADE JÚNIOR, 2011; TRINDADE JÚNIOR e RIBEIRO, 2009).

$\mathrm{Na}$ abordagem da urbanização na Amazônia, relacionando ao papel regional desempenhado por algumas cidades é preciso direcionar a análise "pelas fortes centralidades que aí se materializam por meio de fluxos, a ponto de contribuírem significativamente para o ordenamento do espaço regional em que se inserem" (TRINDADE JÚNIOR, 2011, p.04)

A noção de centralidade captada em Trindade Jr. e Ribeiro (2011, p. 21) é relativa a um dado contexto sócio-espacial e se destaca pela tendência de fluxos de caráter centrípeto em relação ao contexto intra-urbano, ou em relação à infraestrutura ofertada e a densidade técnica de atividades econômicas e sociais que se concentram neste contexto. 
Seguindo esta abordagem a noção de centralidade é aqui considerada a partir da convergência dos fluxos, em relação a infraestrutura econômica de Araguaína que é utilizada e reutilizada para responder a estes fluxos. Como espaço central da região periférica, Araguaína cumpre a função de supridora de produtos primários, dos mercados interno e externo, exercendo controle sobre a região.

A afirmativa de Sposito (2007, p. 235) de que "grande parte dos papéis desempenhados por cidades médias está diretamente associado ao desenvolvimento de atividades agropecuárias em suas áreas rurais", colabora com o entendimento de uma das funções exercidas por Araguaína.

Os resultados da pesquisa direta evidenciam centralidade da função urbano-regional de apoio à agropecuária exercida por Araguaína; de agroindústrias, comércio e serviços especializados, instituições públicas e privadas, as vias de circulação; e a apropriação do marketing de capital do boi do gordo, no qual se discute mais detalhadamente a seguir.

\section{AS AGROINDÚSTRIAS DE ARAGUAÍNA: MEDIAÇÃo COM O MERCADO MUNDIAL}

Atuando como centro de decisão, centralidade capitalista na regional, Araguaína participa com expressivo percentual na exportação estadual de carne bovina e derivados, embora mantenha-se na segunda posição de produtora de bovinos com efetivo de 226.000 animais, inferior ao quantitativo de 282.600 bovinos registrado em Araguaçu, localizada no extremo sul estadual (IBGE,2006). A produção é regional e na cidade concentram-se as agroindústrias instaladas ou territorialmente articuladas, conferindo controle da cidade sobre a região, inserida na divisão territorial do trabalho mundial.

A presença de agroindústrias relaciona-se essencialmente ao beneficiamento da produção pecuária regional e realizam mediação ao mercado mundial. Será compreendida como "indústrias que compram ou recebem produtos agropecuários para transformá-los em produtos industrializados são usualmente agrupadas sob a denominação genérica de agroindústrias” (SZMRECSÁNYI, 1997, p. 59).

“As empresas mais poderosas escolhem os pontos que consideram instrumentais para sua existência produtiva" (SANTOS e SILVEIRA, 2008, p. 294). As agroindústrias da produção pecuária, na sua maioria, estão instaladas no município de Araguaína e com menor 
presença em municípios limítrofes, resguardando as relações territoriais entre a cidade central e sua região.

São agroindústrias: (Minerva S.A, Másterboi, Boiforte e Associação do Comércio e Varejo de Carnes Frescas de Araguaína - Assocarne); laticínios (Biana, Asa Agroindustrial, Leitbom S.A., Filadélfia Indústria e Comércio de Laticínios); curtumes (Durlicouros, e Tocantins curtimento de couro LTD); nutrição animal (Premix, Agromaster, Nitrosal, Agrocam, Suzuki); extração do colágeno do bovino (Gelnex).

Filiais de grandes empresas nacionais e locais adotam estratégia de mercado com localização, situando-se ao longo das rodovias Belém-Brasília e TO-222, principais vias de circulação regional, tornando-as de vital importância para a centralidade exercida pela cidade. A decisão locacional dessas empresas é influenciada pela disponibilidade de mão-de-obra, proximidade com a matéria-prima e vias de circulação, que possibilitam acesso aos portos de Itaqui na capital maranhense.

As agroindústrias passam a ter maior expressividade com os frigoríficos localizados em Araguaína e nos municípios limítrofes como Nova Olinda (ao sul) e Wanderlândia (ao norte) beneficiando a produção, sobretudo visando exportação, mas também aos mercados nacionais e locais. Nas margens das rodovias Belém-Brasília e TO-222 no contato com o estado do Pará, encontra-se os quatro frigoríficos da região, dois em cada rodovia. Neste caso, em relação à cidade, possuem localização periférica urbana, mas uma centralidade regional. A posição nas rodovias é estratégica, pois colabora no acesso da matéria-prima como na circulação da produção beneficiada.

Araguaína centraliza produção pecuária destinada ao mercado mundial exportando um terço de toda produção estadual de carne, miúdos e couro bovino. Na condição de exportador municipal a indústria frigorífica Minerva é principal empresa ${ }^{1}$. A participação é complementada pelo Frigorífico Boi Forte e o Masterboi. Cada unidade frigorifica possuindo capacidade de produção para abater entre 700 a 900 bois por dia (BRASIL, 2010).

O frigorifico Minerva possui como principais sócios o fundo de investimentos Salic (UF) Limited de origem árabe, os grupos BRF (das marcas Sadia e Perdigão) e VDO Holding dominados por investidores estrangeiros. Já a Masterboi tem sede no Nordeste brasileiro com

\footnotetext{
${ }^{1}$ O grupo JBS instalou em Araguaína uma unidade frigorifica no ano de 2015. A empresa detém marcas como Friboi, Seara, Swit, e é líder mundial do mercado de carne bovina. Mantém a mesma lógica de localização e produção das outras frigorificas, mas presumindo-se que de forma mais agressiva. 
filiais no Norte e Centro Oeste; enquanto que o Boi Forte, é empresa local formada por capital goiano-tocantinense.

O consumo de carne bovina da cidade de Araguaína tem maior produção organizada pela Assocarne, responsável pelo abatimento e encaminhamento da carne sem nenhum beneficiamento ao consumidor, e em menor quantidade com beneficiamento dos frigoríficos.

O gado de baixa qualidade é reservado ao consumo local, como vacas descartadas pela cidade, no entanto, com preço similar ou até mesmo maior, do que os praticados em cidades não produtoras.

Quem comanda o mercado de exportação da carne é o Frigorífico Minerva, atuando na produção e comercialização de carne bovina, couro e boi vivo, e, ainda, está entre os três maiores exportadores do país. No Tocantins movimenta o maior valor financeiro por domicilio fiscal em quantia de US\$ 63,4 milhões anuais, participando em 18,5\% das exportações estaduais, sendo apenas superado pela multinacional Bunge Alimentos, atuante em municípios produtores de soja (BRASIL, 2010).

Gráfico 1 - Municípios exportadores de carne bovina no Tocantins (2010)

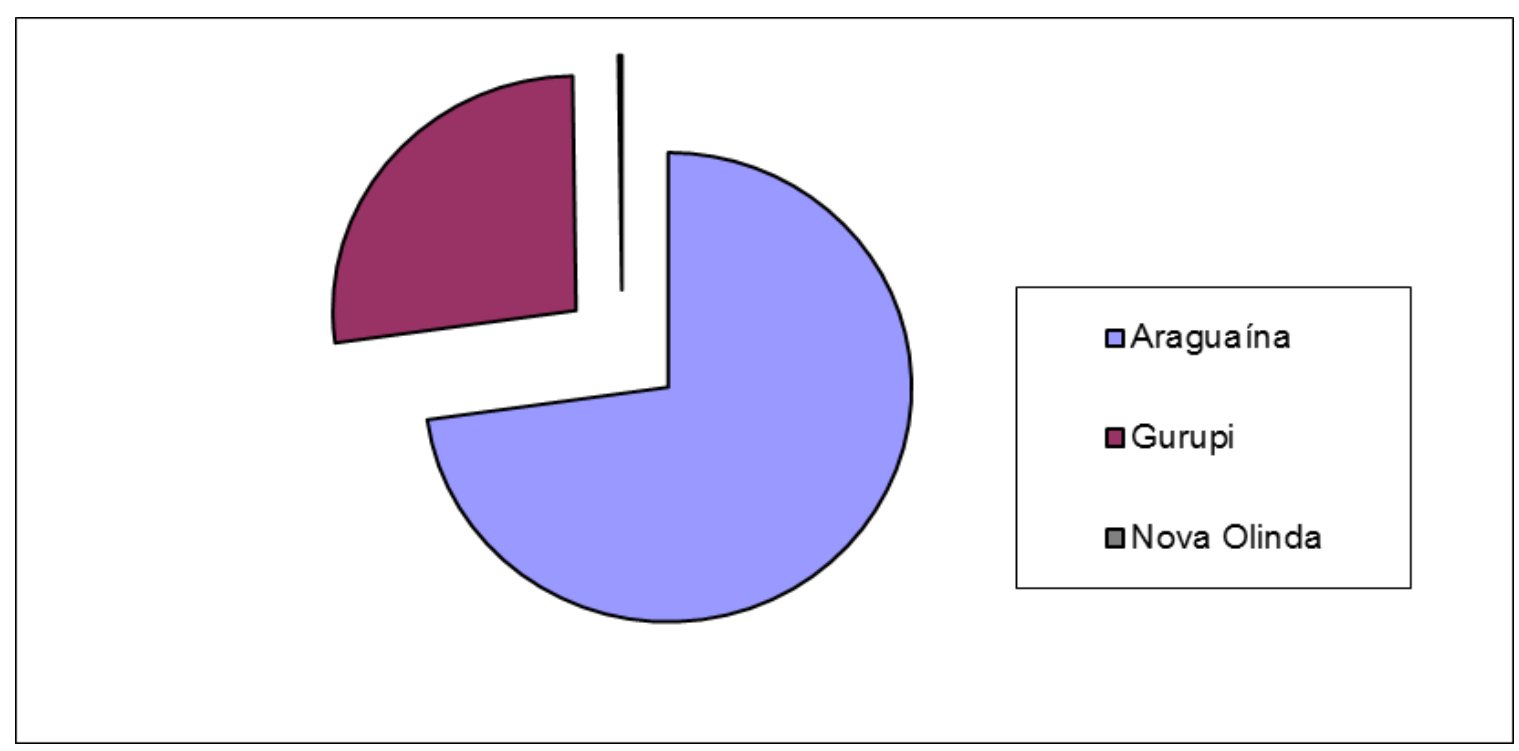

Fonte: Brasil, 2010. Elaboração do autor.

A distribuição da exportação de carne bovina proporciona expressividade de Araguaína no cenário estadual, pois $73 \%$ da produção que chega ao mercado internacional têm origem nesta cidade. Nova Olinda, com unidade frigorífica distante à $40 \mathrm{~km}$ de Araguaína, e 
economicamente articulada com esta, tem participação $0,1 \%$. Gurupi, município ao sul tocantinense, participa em 23\% neste mercado (Gráfico 1).

Dados coletados em pesquisa direta revelam que o Frigorífico Minerva adquire 700 bovinos a cada dia, com origem em mais de trinta municípios do Norte estadual (70\%) e do Sudeste do Pará (30\%), principalmente os municípios de São Geraldo do Araguaia e Piçarra, neste caso formando área de influência de Araguaína.

$\mathrm{Na}$ última década, Araguaína tem alcançado significativo mercado externo, estendendo a produção para vinte países em diversos continentes e blocos econômicos. Até o ano 2000 a balança comercial municipal apontava incipiente exportação de 451 mil dólares, em espetacular salto para 65 milhões de dólares uma década depois (BRASIL, 2010).

A pecuária de exportação tem o Oriente Médio como principal mercado consumidor, destino de mais que metade da produção, com relevância para Egito e Irã, consumidores de 38\%; já no MERCOSUL, Venezuela e Chile são responsáveis pela participação de 18,5\% do bloco econômico; há ainda consumidores na Europa Oriental, com proeminência para o mercado russo, África e Ásia (Gráfico 2).

Gráfico 2 - Principais países de destino da produção pecuária de Araguaína-TO (2010)

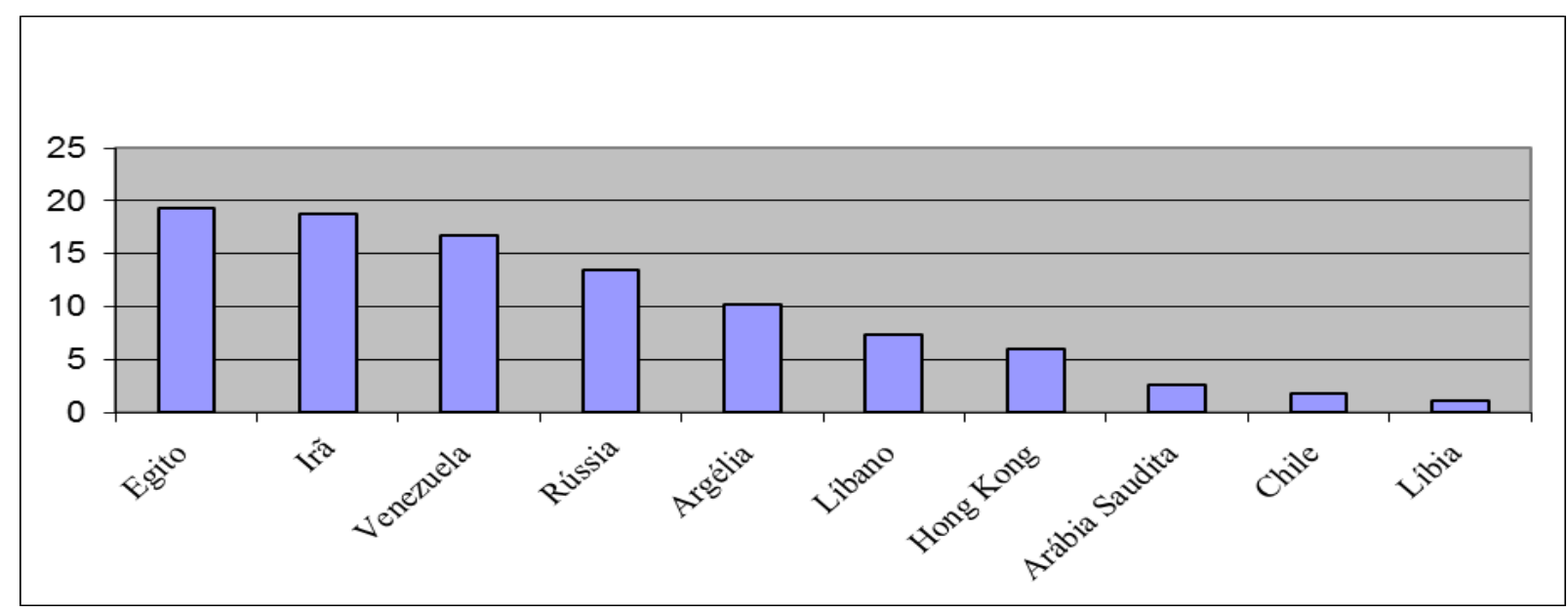

Fonte: Brasil, 2010. Elaboração do autor.

A União Européia faz restrições à carne produzida no Tocantins e motiva uma força tarefa do governo estadual, com diversas visitas aos países do continente e de técnicos de instituições de sanidade européias ao estado (TOCANTINS, 2009). A atuação estatal sofre pressão de empresas e produtores pecuaristas do estado para obter liberação de mercado com política prioritária de governo. 
Os curtumes participam com beneficiamento do couro bovino para exportação e mercado nacional. São duas agroindústrias instaladas na rodovia Belém-Brasília, no município de Wanderlândia, além da intermediação da produção, em Araguaína. A Durlicouros, empresa nacional da produção de couro, não exporta diretamente de sua filial, transferindo o produto para matriz no Rio Grande do Sul que de lá atende aos mercados europeus e asiáticos. $\mathrm{O}$ curtume Tocantins, destina produção ao mercado nacional.

Os laticínios têm apresentado aumento em quantidade e de produção, acompanhando a maior ascensão nos últimos anos da bacia leiteira na região, mesmo que ainda esteja bastante incipiente, não representando concorrência com a tradicional pecuária de corte (IBGE, 2006). O município de Araguaína abriga quatro unidades agroindustriais que produzem leite pasteurizado em saco plástico de litro, iogurte, bebida láctea e queijos; que são distribuídos no mercado tocantinense e no Maranhão.

Para nutrição animal as agroindústrias de abastecimento do mercado local e regional produzem rações e suplementos minerais para alimentação bovina da pecuária de corte extensiva, bem como para produção de pastagens. São quatro unidades fabris classificadas como micro-agroindústrias e tem localização no Distrito Agro-industrial de Araguaína.

A extração de colágeno do couro bovino é atividade desenvolvida pela Gelnex, filial de agroindústria de porte nacional. O colágeno produzindo a partir do couro bovino e utilizado na fabricação de gelatinas em outras unidades da própria empresa, mas em breve deve completar o ciclo de produção na filial araguainense, como informado no site da empresa.

\section{ESPECIALIZAÇÃO DE COMÉRCIO E SERVIÇOS PARA PECUÁRIA}

As atividades de apoio a pecuária, marcantes na infraestrutura urbana, estão inseridas na diversificada distribuição de bens e serviços concentrados por Araguaína, destacando o setor terciário pela importância na função regional.

As Avenidas Cônego João Lima, Santos Dumont e Bernardo Sayão transformam-se em corredores de especialização na produção pecuária e no comércio de bens e serviços com origens diversas de fornecedores multinacionais, nacionais e locais.

O comércio especializado em lojas de venda de produtos agropecuários; agregando-se as concessionárias de multinacionais, para venda e manutenção de tratores; complementados por comércio de peças e manutenção de tratores; de transportadoras de gado; de intermediários; postos de combustível; de caminhões-gaiola; de indústrias artesanais da 
fabricação e manutenção de carrocerias, ou em artigos de couro para selaria, ferragens e marcas para bovino; na assessoria técnica em áreas de afinidade, entre as principais atividades identificadas em pesquisa de campo, praticamente localizadas entre os corredores comerciais referidos e as principais rodovias.

Por meio destas empresas há intenso fluxos de mercadorias fornecidas por multinacionais, nacionais e locais, que são transformadas em bens e serviços usados como insumos de apoio aos produtores pecuaristas.

As lojas de vendas de produtos agropecuários são compostas por filiais de empresas com sede no estado de São Paulo, Goiás e Mato Grosso; as com matriz local que formam maioria quantitativa em número de estabelecimentos. A atuação regional das empresas tem distinção definida pelo capital disponível para investimentos, diversidade, preços dos produtos e pela extensão de propriedades por pecuaristas locais para o Sudeste Paraense, confirmando pesquisas anteriores de Becker (1990) que sinalizavam para cidades na franja da floresta com função de base logística para avanço da fronteira agrícola na Amazônia.

As filiais de empresas sediadas nas regiões Sudeste e Centro-Oeste acompanham a agropecuária para o Sudeste Paraense, instalando filiais e nomeando empresas representantes em cidades com localização estratégica.

As matrizes locais expandem território na porção norte tocantinenses avançando nas fronteiras para as mesorregiões Sul Maranhense até município de Balsas, Sudeste Paraense, municípios de São Geraldo do Araguaia, Piçarra, Redenção, Xinguara, Pacajá, Marabá e São Felix do Xingu, dentre outros. Contribuem para extensão do comércio pecuário ao Sudeste Paraense, e a expansão da atividade, realizada com participação de pecuaristas residentes em Araguaína.

A diversidade de produtos é um atrativo de mercado local, segundo comerciante do ramo: "Araguaína tem uma diversidade maior de produtos, e o nosso cliente sabe que vindo aqui em Araguaína, vai achar, encontrar o que precisa - desde o produto mais simples ao mais especializado" (Pesquisa direta, 2011).

Em geral há uma variação de produtos oferecidos no comércio especializado, com exceção de algumas que atendem demanda exclusiva em venda de sementes para pastagens. A maioria da variedade de produtos comercializados é destinada ao uso da pecuária, já para agricultura são mais raros e suprem apenas agricultura de subsistência. Combinado com produtos para pecuária, apenas uma loja tem como objetivo atender produtores de soja dos municípios tocantinenses de Wanderlandia e Darcinópolis.

Silva, 2017 ISSN 0104-5490
204 
As concessionárias de multinacionais para venda e manutenção de tratores e implementos agropecuários dispõem de quatro unidades em Araguaína, a John Deere, Massey Ferguson, New Holland e Valtra. Expandem-se instalando novas filiais em cidades do Sudeste Paraense, com atuação específicas e delimitada, cada uma com o domínio de territórios específicos.

Complementar às multinacionais, e com empresas de sede local, estabelece-se uma diversidade de comércio de peças, implementos, manutenção e aluguel de tratores de pneu e esteira, visando como clientes, sobretudo os pequenos proprietários.

A aquisição dos bovinos e o transporte do gado vivo estão sujeitos a serviços terceirizados, participação de intermediários e complementado por serviços de apoio na rodovia Belém-Brasília. Intermediários participam da compra e venda de gado, inclusive também desempenhada por significativa quantidade de fazendas que mantêm escritórios na cidade para esta finalidade.

Os frigoríficos terceirizam o transporte para empresas especializadas, que por sua vez, contratam caminhoneiros e caminhões com carroceria do tipo gaiola utilizadas para transporte do gado vivo das fazendas da região até frigoríficos.

O Posto Boiadeiro, posto de combustível situado na área urbana da rodovia BelémBrasília, centraliza ponto de apoio aos caminhoneiros e caminhões e outros usuários que se encontram de passagem pela movimentada rodovia. Em geral os transportadores de "gaiolas" ficam estacionados neste e outros postos da rodovia, aguardam contrato de carga e utilizam serviços diversos como alimentação, bebidas e hospedagem. Serviços de mecânica pesada em caminhões são bem comuns ao longo do trecho urbano da rodovia que servem aos caminhõesgaiola e os outros que transportam mercadorias entre as regiões do país. É notável também a fabricação e manutenção de carrocerias de madeira, as gaiolas.

Indústrias artesanais são responsáveis pela fabricação e venda de ferragens usadas na construção de curral, carrocerias, pontes etc.; de artigos de couro para selaria e acessórios para os peões (vaqueiros); marcas personalizadas utilizadas para sinalizar o bovino, espraiados pelos espaços mais valorizados como as Avenidas Cônego João Lima e Bernardo Sayão e outras ruas.

Araguaína é distribuidora de produtos industrializados nacionais e mundiais utilizados na produção pecuária, com origem nas principais indústrias farmacêuticas, agroquímicas (herbicidas, fertilizantes, inseticidas, etc.), nutrição animal, máquinas e equipamentos. Participam de forma mais expressiva as multinacionais, (Merial, Pfizer, Stihl, Bayer, Dow Silva, 2017 ISSN 0104-5490 205 
AgroSciences) seguida por grandes grupos nacionais (Gerdau, Ourofino Agronegócio, Clarion, Nortox, Valée); complementado por indústrias locais. No geral as empresas fornecedoras possuem atuação em todos os segmentos do agronegócio nacional e mundial.

A saúde animal, ao lado da alimentação, mostra-se como preocupação recorrente no processo produtivo da pecuária bovina direcionado ao mercado mundial. Os medicamentos veterinários distribuídos no comércio são de domínio das grandes empresas farmacêuticas mundiais, que controlam a produção e venda. Constatou-se maior número de empresas fornecedoras, de origem externa, sendo nove empresas multinacionais e quatro nacionais (Tabela 1).

Tabela 1 - Perfil das empresas fornecedoras de insumos, máquinas e implementos para agropecuária de Araguaína-TO / 2011

\begin{tabular}{|c|c|c|c|c|c|c|}
\hline \multirow[t]{2}{*}{ Característica da produção } & \multicolumn{2}{|c|}{$\begin{array}{l}\text { Fornecedores } \\
\text { multinacionais }\end{array}$} & \multicolumn{2}{|c|}{$\begin{array}{l}\text { Fornecedores } \\
\text { nacionais }\end{array}$} & \multicolumn{2}{|c|}{$\begin{array}{l}\text { Fornecedores } \\
\text { locais }\end{array}$} \\
\hline & Quant. & $\begin{array}{l}\% \text { do } \\
\text { total }\end{array}$ & Quant. & $\begin{array}{l}\% \text { do } \\
\text { total }\end{array}$ & Quant. & $\begin{array}{l}\% \text { do } \\
\text { total }\end{array}$ \\
\hline Medicamentos veterinários & 9 & 32,0 & 4 & 21,0 & - & - \\
\hline $\begin{array}{l}\text { Agroquímicos (herbicidas, fertilizantes, } \\
\text { inseticidas, etc.) }\end{array}$ & 5 & 17,9 & 4 & 21,0 & - & - \\
\hline Nutrição e suplemento animal & 4 & 14,3 & 5 & 26,3 & 2 & 66,7 \\
\hline Tratores e implementos agrícolas & 4 & 14,3 & - & - & - & - \\
\hline Sementes para pastagens & - & - & 3 & 15,8 & 1 & 33,3 \\
\hline Arames de aço e acessórios para cercas & 1 & 3,6 & 1 & 5,3 & - & - \\
\hline Melhoramento genético & 3 & 10,7 & - & - & - & - \\
\hline $\begin{array}{l}\text { Ferramentas motorizadas (motor serra, } \\
\text { roçadeiras, etc.) }\end{array}$ & 1 & 3,6 & - & - & - & - \\
\hline Implementos e equipamentos agrícolas & 1 & 3,6 & 1 & 5,3 & - & - \\
\hline Análise técnica (de alimentos e água) & - & - & 1 & 5,3 & - & - \\
\hline Total & 28 & 100,0 & 19 & 100,0 & 3 & 100,0 \\
\hline
\end{tabular}
Fonte: Pesquisa de campo ( 2011). Org.: Próprio autor.

As vacinas destacam-se como principal medicamento veterinário comercializado. $\mathrm{O}$ Tocantins é zona livre de febre aftosa, condição que mantém realizando anualmente duas campanhas de vacinação imunização contra esta, e outras doenças. Conta com rigorosa fiscalização da Agência de Defesa Agropecuária (ADAPEC), com poderes de bloquear a movimentação de compra e venda do rebanho e interditar a propriedade, em caso de não cumprimento das exigências de sanidade animal. A imunização do rebanho bovino atinge 99\% da meta estipulada, movimentando o comércio de apoio à pecuária, com venda de vacinas (TOCANTINS, 2009). 
O status sanitário é a condição imprescindível para exportação da carne ao mercado mundial, prerrogativa que no Brasil, é concedida a 15 Unidades de Federação, garantindo. Em 2003 o Tocantins recebeu este status sanitário, podendo ampliar o mercado externo. O mesmo ocorreu no sudeste do estado do Pará no ano de 2008, inclusive em municípios limítrofes à região de Araguaína, possibilitando um alargamento do rebanho abatido e beneficiado para exportação, sob comando de Araguaína (BRASIL, 2009).

Indústrias nacionais de produtos veterinários, nutrição e suplemento animal, utilizam como estratégia a distribuição de produtos por filiais no comércio varejista em Araguaína. A Agroquima, sediada em Goiânia-GO e a Alvorada produtos agropecuários de Campo GrandeMS, ambas possuindo matriz de agroindústria em medicamentos veterinários e nutrição animal. O grupo Gasparim, do interior paulista, utiliza a mesma estratégia de distribuição de sementes para pastagens e produtos de nutrição animal.

A Premix de atuação nacional, optou por instalar unidade fabril em Araguaína e com mais três micro agroindústrias de sede local produzem suplementos minerais e rações utilizadas como nutrição animal.

Os fornecedores locais possuem atuação principiante diante das multinacionais e nacionais, pois são os fabricantes de ferragem para curral e de artigos de couro para selaria, produtos com menor valorização no mercado.

Araguaína é espaço periférico capitalista de produção, mas não para consumo de produtos que exigem maior tecnologia na produção, como medicamentos, tratores e agroquímicos. O quantitativo de $56 \%$ de fornecedores multinacionais indica dependência da produção primária das tecnologias estrangeiras (Tabela 1).

\section{NO ESPAÇO URBANO CORREDORES ESPECIALIZADOS PARA A REGIÃO}

O comércio e serviços para a pecuária tornam-se notórios na infraestrutura urbana da cidade, com formação de corredores especializados nas principais avenidas, vias de acesso e saída, conectados à rodovia Belém-Brasília e TO-222, que também compõem um desses corredores. A espacialização das atividades de apoio à pecuária na cidade de Araguaína é formada em três principais corredores.

São as Avenidas Cônego João Lima, Santos Dumont e Bernardo Sayão. Nestas predomina o uso comercial, mas é possível, mesmo que em menor quantitativo, encontrar imóveis para moradia. 
A Avenida Cônego João Lima, perpendicular a rodovia federal, é o principal eixo comercial e via de acesso e saída, que conecta a cidade com a região. A partir de seu início na rodovia, segue no sentido oeste-leste, atravessando o centro da cidade onde forma a maior concentração de comércio, serviços, instituições financeiras e rede bancária.

O agrupamento quantitativo de comércio e serviços para apoio à pecuária também é mais significativo na Avenida Cônego João Lima com um terço do total e representando maior especialização (Figura 2). Tem início logo no contato com a rodovia e se estende até o córrego Neblina, divisando com o centro da cidade. Entre as atividades de apoio à pecuária desenvolvidas destacam-se as lojas especializadas na comercialização de produtos agropecuários; as instituições financeiras; fabricação e venda de ferragens para curral e de artigos de couro para selaria; e presença de intermediário da compra e venda de bovinos.

Figura 1 - Infraestrutura urbana de apoio à pecuária na Av. Cônego João Lima.
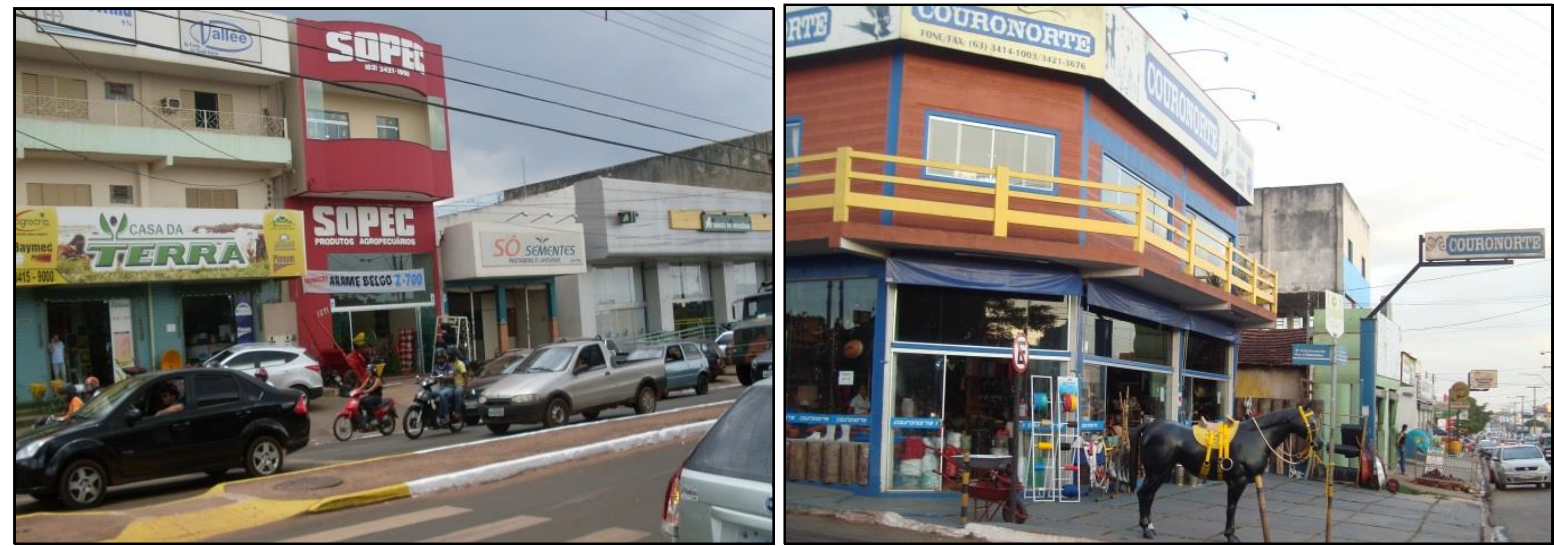

Fonte: Próprio autor, 2011.

A Avenida Santos Dumont também iniciou com a rodovia federal, como via de acesso e saída rodoviária para as regiões brasileiras, já que nela está localizado o terminal rodoviário; além de vinculação com a região e Sudeste Paraense. Estendida no sentido oeste-leste por 2,2km até encontrar-se com a Avenida Cônego João Lima, em ponto de concentração de atividades para apoio à pecuária (Figura 2). É uma avenida de predominância comercial com presença hotéis, locadoras de automóvel, material de construções, ferro velho, dentre outras.

Destacam-se no apoio a pecuária as lojas que comercializam exclusivamente sementes para pastagens, os intermediários da compra e venda de bovinos, manutenção e aluguel de tratores e implementos agrícolas, produtos agropecuários, ferragens para curral. A principal 
expressão econômica evidenciada nesta avenida é a presença de duas concessionárias de multinacionais para venda e manutenção de tratores e implementos agrícolas.

Figura 2 - Espacialização das atividades de apoio à pecuária em Araguaína-TO

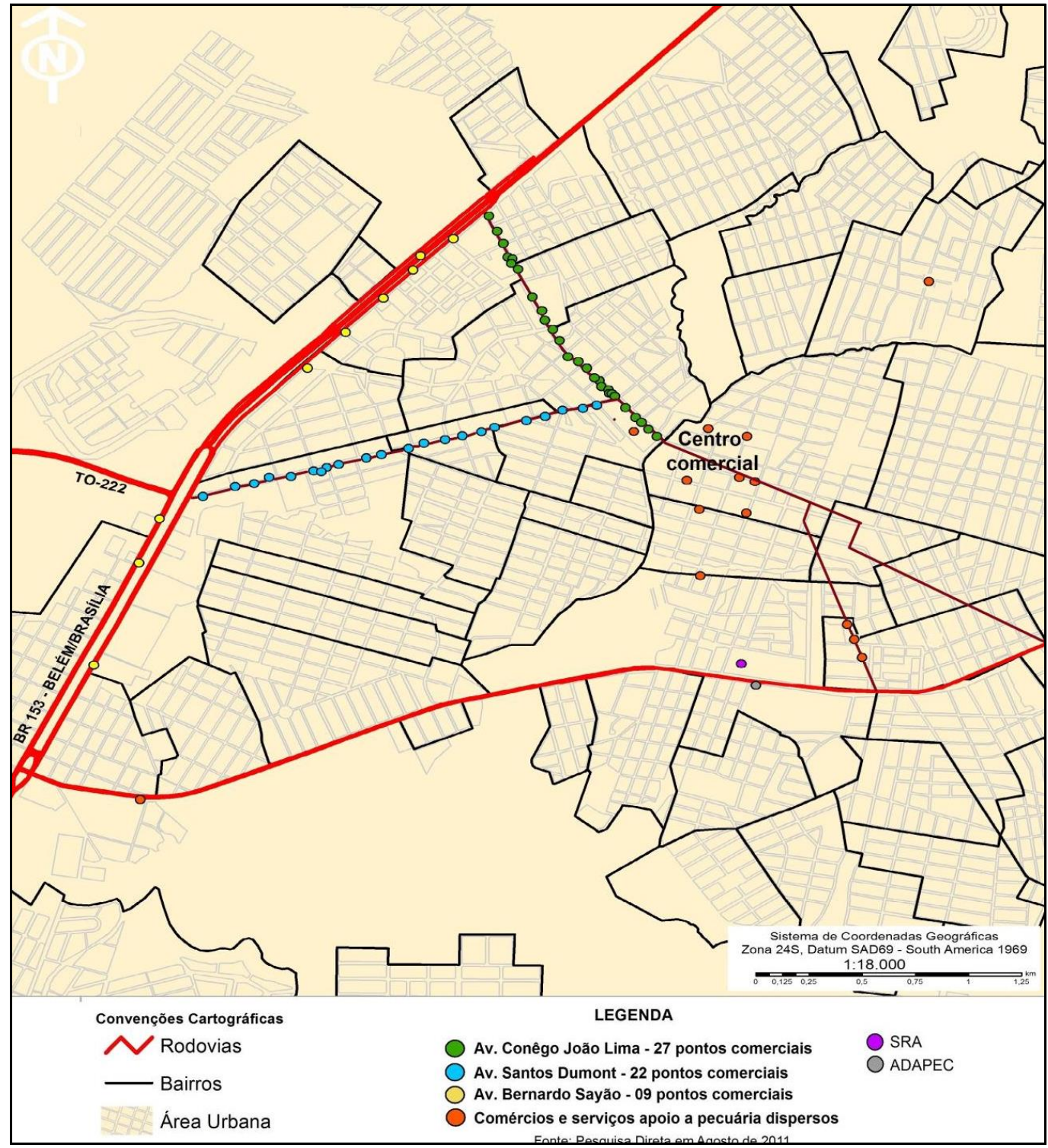

Fonte: IBGE (2010), pesquisa de campo (2011). Organizado pelo autor

A duplicação da rodovia Belém-Brasília na área urbana da cidade forma a Avenida Bernardo Sayão (Figura 2). A quantidade de serviços na rodovia é bem intensa visando atender ampla movimentação de caminhões, com postos de combustíveis, oficinas mecânica para grandes veículos, restaurantes, etc. $\mathrm{O}$ apoio à pecuária nesta avenida tem destaque para tratores e implementos agrícolas, representadas por duas concessionárias de multinacionais e 
oficinas para manutenção; com presença ainda de lojas de produtos agropecuários, e de ferragens para curral.

A infraestrutura urbana de apoio à pecuária está concentrada nestas três avenidas, embora possa ser encontrada em diversas outras localidades dispersas pela cidade. A exemplo da avenida João de Sousa Lima, via urbana ligação com o estado do Maranhão, conectado o centro da cidade com Avenida Filadélfia, nome recebido pela rodovia TO-222 no perímetro urbano de Araguaína. Nestes pontos dispersos são encontradas lojas de produtos agropecuários, intermediários, assessoria técnica, instituições públicas, fabricação e conserto de carrocerias gaiolas, melhoramento genético, sindicato Patronal, ferragens para curral, dentre outras (Figura 2).

\section{ESTÍMULOS E MARKETING PARA CAPITAL DO BOI GORDO}

A manutenção da condição de capital do boi gordo conta com estímulos do governo estadual, instituições públicas e privadas por meio de fiscalização, assistência técnica, incentivos financeiros e o marketing. A Agencia de Defesa Agropecuária (ADAPEC) atua na fiscalização e defesa garantindo a sanidade animal, imprescindível para exportação da produção. O financiamento é proporcionado pelo Banco da Amazônia (BASA), Banco do Brasil, e pelo banco privado Bradesco.

Araguaína beneficia-se de investimentos do governo estadual como a pavimentação de rodovias de circulação regional e nos incentivos fiscais e financeiros. A pavimentação das rodovias do entorno facilitou o escoamento da produção pecuária regional que chega até a cidade central para beneficiamento.

Incentivos fiscais e financeiros estaduais favorecem a capital do boi gordo: isenção da carga tributária do ICMS (Imposto Sobre Circulação de Mercadorias e serviços) para empresas exportadoras, e redução da alíquota de $17 \%$ para $3 \%$ sobre o valor do gado vivo destinado ao abate; crédito presumido de $75 \%$ do imposto devido nas saídas de couro curtido e industrializado; e missões de negócios para divulgação do potencial do Tocantins em diversos países (TOCANTINS, 2009).

A Universidade Federal do Tocantins no campus de Araguaína tem atuado na agropecuária desenvolvendo pesquisas na área de concentração de produção animal por meio de programa de Pós-Graduação em Ciência Animal Tropical (PPGCat) e dois cursos de graduação, sendo em medicina veterinária e outro de zootecnia. O PPGCat iniciou suas 
atividades em 2006 com a criação do mestrado e em 2009 o doutorado, formando mais de 100 mestres e 30 doutores, mão de obra altamente especializada em produção animal no bioma Amazônia e a relação solo, planta, animal; com maior proeminência para pecuária (UFT, 2012).

Empresas multinacionais, algumas com escritórios na cidade, oferecem serviços para o melhoramento genético do rebanho bovino. Quanto à técnica de inseminação artificial já é amplamente dominada e praticada em fazendas do município e região. Nota-se nestes redutos a presença da Associação Brasileira de Criadores de Zebu (ABCZ) que disponibiliza banco de dados e tecnologia empregada na melhoria genética.

Das instituições que têm proporcionado apoio à pecuária a de maior relevância para o setor, sem dúvida, é o Sindicato Rural de Araguaína (SRA) entidade patronal representativa dos produtores pecuaristas de Araguaína e sua influência atuando na definição de estratégias de mercado, divulgando informações por meio de cursos, palestras, mídias, etc. O poder territorial da pecuária no estado e na região, também poder ser expresso pela representatividade de políticos filiados nesta entidade.

O SRA se credencia como a maior responsável pela firmação de Araguaína como capital do boi gordo. Realiza dois grandes eventos anuais de finalidade econômica: a Exposição Estadual Agropecuária de Araguaína (EXPOARA) e, junto com outras instituições, a Feira de Negócios, Indústria e Agroindústria do Tocantins (FENIAGRO). A EXPOARA se configura um dos principais eventos e festas de Araguaína e região, com participação de 200 mil pessoas e movimentação de quantia superior a R\$ 30 milhões durante os dez dias de sua realização em 2010 (SRA, 2011).

Atuando na definição de estratégias de mercado, consta na pauta de prioridades apresentadas pelo SRA que a qualidade da carne produzida deve ser de acordo com as exigências do mercado mundial:

$$
\begin{aligned}
& \text { O sindicato hoje tem se preocupado, com relação a isso aí [qualidade da carne]; } \\
& \text { primeiro tem trabalhado com o produtor, sempre com ideologia de tecnologia, } \\
& \text { porque hoje se você não tiver um produto de qualidade, o mundo mercadológico da } \\
& \text { carne, exige textura de gordura, maciez [...] e isso se volta à genética, alimentação, } \\
& \text { mineralização e manejo; cabe-se ao sindicato, pegar todo esse aparato tecnológico e } \\
& \text { fazer divulgações para os seus associados [...]. Ë tudo isso é feito com intenção de } \\
& \text { atender o mercado global (Diretor do SRA, 2011) }
\end{aligned}
$$

A instituição vislumbra de forma explicita uma potencial região produtora, favorecida por condições naturais e pela disponibilidade de terras, como afirma diretor do SRA “[...] a melhor pecuária do Brasil está presente em Araguaína, devido ao clima, luz, temperatura, [...] 
e abundância de gente que tem condição de produzir". Portanto com capacidade de competir frente aos mercados de produção nacional.

É uma entidade que busca assegurar o poder econômico e político obtido pelas elites pecuaristas. O poder é expresso pelos donos das terras da região, pois quem dispõe da posse da terra comanda o território e, portanto, a região. A vinculação à Confederação da Agricultura e Pecuária do Brasil (CNA) e pela representatividade expressa pelos principais políticos do município e do estado conferem manutenção do poder.

[...] nós também temos produtores que é deputado, que faz parte do sindicato rural, o senador João Ribeiro é filiado ao sindicato, o atual prefeito de Araguaína é sindicalizado, então precisa ter esse elo da convivência, da necessidade, o sindicato tem e teve com o governo uma porta bastante aberta (Diretor do SRA) (Grifos nossos).

O desenvolvimento capitalista desigual torna-se notório numa região onde as elites pecuaristas comandam as terras, as riquezas e detêm privilégios, dando sentido à pecuária e poder político como pares inseparáveis. O político representante da elite pecuarista é o elo necessário atuando na defesa dos interesses de sua classe, da manutenção, ampliação do poder econômico e social historicamente construído. Esta é uma combinação marcante que se torna perversa em Araguaína.

O discurso de Araguaína como capital do boi gordo é defendido pelo SRA, como uma forma de difundir a imagem de uma cidade rica e prospera e se apropriar de investimentos públicos: "Esse marketing de capital do boi gordo vai durar uma eternidade, nós temos boi gordo o ano inteiro, ninguém vai tirar esse titulo de Araguaína” (Diretor do SRA).

Araguaína, a cidade média em estudo, atua como distribuidora de bens e serviços de apoio à agropecuária, comandando e captando a matéria prima produzida no campo, atuando como mediadora de acumulação da pecuária capitalista, o que contribui para caracterizar cidade média. Ostenta condição de centro de comando da dinâmica urbano-regional, para fomentar o papel de fornecedora de produção primária ao mercado mundial.

Nesse sentido, cidade média também pode ser reconhecida por suas relações de intermediação e capacidade de subordinar o campo, que por sua vez, é condição imprescindível na execução de seu principal papel econômico: centro urbano provedor de matéria prima para exportação, portanto, inserida em processo de reprodução e ampliação do capital. 


\section{CONSIDERAÇÕES FINAIS}

O planejamento estatal para a Amazônia determina com intensa influência econômica e urbana a conformação espacial de Araguaína. A mediação do governo no espaço torna-se uso do interesse privado a mercê dos interesses de empresas nacionais e globais.

Araguaína e sua região são interesse da expansão do capitalismo brasileiro com a incorporação de fronteiras agrícolas, transformada rapidamente em agropecuária de exportação a fim de atender à demanda por maior produção de alimentos, necessidade da urbanização crescente, e passa a desempenhar funções especificas na divisão territorial do trabalho fornecendo carne bovina para mercados locais, regionais e inter-regionais e ao mercado mundial.

Exerce centralidade na produção e exportação da agropecuária tornando-se uma das cidades da Amazônia brasileira essencial para ampliação do processo de acumulação do capitalismo e mantém, por meio das elites locais, discurso e ações que asseguram poder da pecuária local e regional, como atividade econômica geradora de riquezas.

Estrutura comércio especializado e agroindústrias de suporte à pecuária regional e se conecta diretamente ao mercado mundial por meio da produção e da centralidade urbanoregional, no entanto, mantém condição periférica na produção primária e na dependência de produtos industrializados de empresas multinacionais e nacionais para subsidiar a agropecuária

É a centralidade urbano-regional de uma cidade que se constitui média em função de uma atividade econômica que a posiciona como um importante ponto de apoio relacionado à sua existência e aos agentes que a controlam.

A pecuária é uma atividade que mantém a terceira posição em expressão econômica, mas assume importante papel na produção do espaço urbano. Se expande em serviços, comércio e indústria e isto vai proporcionar o perfil principal para a cidade. Daí consolida a importância de Araguaína e sua centralidade na relação cidade-região ou urbano-regional.

O poder econômico e político historicamente construído é mantido, estendido, e suficiente para que a elite pecuarista mantenha-se com destaque na produção do espaço urbano da cidade.

A pecuária utiliza os espaços valorizados de Araguaína nas principais ruas e avenidas que se conectam as rodovias e acesso a região. No entanto, é preciso ponderar que o uso capitalista da cidade não é exclusivo desta atividade, mesmo que esta se aproprie do 
marketing e discursos da capital do boi gordo e dos investimentos públicos direcionados para esta finalidade.

\section{REFERÊNCIAS}

BECKER, B. K. Amazônia. São Paulo: Ática, 1990.

BRASIL. Ministério do Desenvolvimento, Indústria e Comércio Exterior, 2010. Balança comercial, Exportação no Tocantins e municípios entre 1990 a 2010 (empresas e produtos). Disponível em: 〈http://www.mdic.gov.br $>$. Acesso em 20/out. /2011.

CASTELLO BRANCO, M. L. Cidades médias no Brasil. In: SPOSITO, E. S. SPOSITO, M. E. B. SOBARZO, O. (Org.). Cidades médias: produção do espaço urbano e regional. São Paulo: Expressão Popular, 2006. p. 245-277.

CORRÊA, R.L. Construindo o conceito de cidade média. In: SPÓSITO, M. E. B. (Org.). Cidades médias: espaços em transição. São Paulo: Expressão Popular, 2007. p. 23 -32

IBGE. Censo Demográfico de Goiás 1960. VII recenseamento geral, Rio de Janeiro: IBGE, 1974.

28/10/2011

Censo Agropecuário 2006. Disponível em <http://www.ibge.gov.br $>$ Acesso em

Regiões de Influências das cidades (REGIC) 2007. Rio de Janeiro: IBGE, 2008. Disponível em: <http://www.ibge.gov.br/home/geociencias/geografia/regic.shtm>. Acesso em 16/out. /10

. Produto Interno Bruto dos Municípios em 2009. Tabela elaborada no Banco de dados agregados. Disponível em: <http://www.sidra.ibge.gov.br>. Acesso em 28/12/10.

$$
\text { Censo demográfico 2010. Disponível em }
$$

<http://www.ibge.gov.br./home/estatistica/populacao/censo2010/default.shtm>. Acesso em 20/abr./2011.

LEFEBVRE H. O Direito à cidade. Trad. Rubens Eduardo Frias. São Paulo: Centauro, 2001. SANTOS, M.; SILVEIRA, M. L. O Brasil: território e sociedade no inicio do século XXI. Rio de Janeiro: Record, 2008

SPOSITO, M. E. B. Cidades médias: reestruturação das cidades e reestruturação urbana. In: SPÓSITO, M. E. B. (Org.). Cidades médias: espaços em transição. São Paulo: Expressão Popular, 2007. p. 233 -253.

SZMRECSÁNYI, T. Pequena História da Agricultura no Brasil. 3 ed. São Paulo: Contexto, 1997.

TOCANTINS (Estado). Lei $\mathbf{N}^{\mathbf{2}} \mathbf{2 . 0 6 0}$, de 17 de junho de 2009. Declara Capital Tocantinense do Boi Gordo o Município de Araguaína. Disponível em <http://www.al.to.gov.br/legislacao.swd>. Acesso em 30/03/2010.

. Secretaria da Agricultura do Estado do Tocantins (SEAGRO). Informações

Gerais do Estado (2009). Disponível em <http://seagro.to.gov.br/>. Acesso em 16/ago. /2011.

TRINDADE JÚNIOR, S.C.C. Cidades Médias na Amazônia Oriental: Das Novas Centralidades à Fragmentação do Território. Encontro da Associação Nacional de PósGraduação e Pesquisa em Planejamento Urbano e Regional, XIV,2011, Rio de JaneiroRJ.

Disponível

em

<http://unuhospedagem.com.br/revista/rbeur/index.php/rbeur/article/view/399 >. Acesso em 10/nov. $/ 2011$. 
TRINDADE JR., S. C.; PEREIRA, J. C. C. Reestruturação da rede urbana e importância das cidades médias na Amazônia oriental. In: SPOSITO, M. E. Cidades médias: espaços em transição. São Paulo: Expressão Popular, 2007. p. 313-342.

TRINDADE JÚNIOR, S.C. C.; RIBEIRO, R. Marabá: Novos agentes econômicos e novas centralidades urbano-regionais no sudeste paraense. In: Encontro da Associação Nacional de Pós-Graduação e Pesquisa em Planejamento Urbano e Regional, XIII, 2009, Florianópolis-SC.

$<$ http://www.anpur.org.br/revista/rbeur/index.php/anais/article/view/3296 $>$. Acesso em 22/09/2011.

UFT. Universidade Federal do Tocantins. Disponível em <http://ww1.uft.edu.br/>. Acesso em 05/fev./2012. 